\title{
Increasing Capacity for Evaluation of Community-Based Organizations: Lessons from the Ohio Equity Institute
}

\section{Daniel M. Walker, $1,2,4,4$;atthew J. DePuccio ${ }^{2}$; Jennifer L. Hefner ${ }^{1,2,3}$; Cynthia Sieck ${ }^{1,2}$; Tory H. Hogan ${ }^{1,2,3}$; Ann Scheck McAlearney ${ }^{1,2,3,4}$; Christine Swoboda ${ }^{2}$; Timothy R. Huerta ${ }^{1,2,4}$}

${ }^{1}$ Department of Family and Community Medicine, College of Medicine, The Ohio State University, $\mathrm{Columbus,} \mathrm{OH}$

${ }^{2}$ The Center for the Advancement of Team Science, Analytics, and Systems Thinking (CATALYST), College of Medicine, The Ohio State University, Columbus, $\mathrm{OH}$

${ }^{3}$ Department of Health Services Management and Policy, College of Public Health, The Ohio State University, Columbus, OH ${ }^{4}$ Department of Biomedical Informatics, College of Medicine, The Ohio State University, Columbus, OH

Corresponding Author: Daniel M. Walker, 460 Medical Center Drive, Suite 520, Columbus, OH 43210, (614) 293-2428, daniel.walker@osumc.edu Submitted July 29, 2021 Accepted November 22, 2021 Published January 28,2022 https://doi.org/10.18061/ojph.v4i2.8469

\begin{abstract}
Background: Community-based organizations (CBOs) play an important role delivering disease prevention and health promotion activities to address community health needs and improve the health of individuals living in their communities. While CBOs play this important role, evaluation of the services they deliver is hampered by limited infrastructure to systematically collect data from these organizations. To address this gap, we report on a case study of the development of the Ohio Equity Institute (OEI) Data Portal. The OEI is a statewide initiative that supports 65 CBOs across Ohio to deliver 3 evidence-based interventions (ie, CenteringPregnancy, Community Health Workers, and Home Visiting) to address infant mortality in underserved populations.
\end{abstract}

Methods: Employing principles of community-engaged stakeholder research and user-centered design, we conducted Plan-Do-Study-Act cycles, including semistructured interviews with 43 key informants, to improve the development, implementation, and use of the OEI Data Portal.

Results: This process identified both technical and implementation challenges, and offered opportunities to make improvements to the data collection system itself as well as to the integration of this system with CBO workflows. These improvements yielded significant gains in terms of the quantity and quality of data submission, ultimately contributing to ongoing outcome evaluation efforts.

Conclusion: Our findings provide important insight into the challenges experienced by CBOs when participating in a statewide $\mathrm{CBO}$ data evaluation infrastructure development and implementation. As Ohio and other states push to expand collaborations between $\mathrm{CBO}$ s and health care organizations, leaders should leverage existing data collection to facilitate a more comprehensive and effective process.

Keywords: Community-based organizations; Infant mortality; Disparities; Evaluation 


\section{INTRODUCTION}

Community-based organizations (CBOs) play an important role delivering disease prevention and health promotion activities to address community health needs. ${ }^{1-3}$ Community-based organizations, which are defined as public or nonprofit organizations that represent their communities and provide health and educational services, 3 facilitate state and national population health initiatives.4-6 Moreover, as of 2017, several state Medicaid programs incentivize health care systems to work with CBOs to address social determinants of health.7 The relationship between CBOs and health care providers is further encouraged by funding programs, such as the Robert Wood Johnson Foundation's Culture of Health. ${ }^{8}$

To participate in these efforts and support partnerships with health care organizations, it is important for CBOs to build evaluation capabilities both to guide their own efforts as well as to demonstrate to funders and other stakeholders that they are effectively implementing evidence-based interventions. ${ }^{9}$ Research suggests that building evaluation capacity, or the ability to perform evaluations, requires CBOs and their staff to buy into the importance of evaluation, commit sufficient resources to collect data, and collaborate with external researchers to develop sustainable evaluation methods. ${ }^{10-13}$

Previous efforts to strengthen internal evaluation capacity have centered on providing CBOs with onsite technical assistance, developing evaluation skills through training programs, and offering interactive web-based systems to guide evaluation design. ${ }^{14-16}$ These efforts emphasize building capacity at the organization level so that CBO managers and staff can take the necessary steps to evaluate the implementation efficacy of interventions, ${ }^{16,17}$ which has been shown to positively affect implementation success.

Although previous research has highlighted the process of building internal evaluation capacity in CBOs, evidence is limited for building evaluation capacity across CBOs. This gap is particularly important because it is not uncommon for multiple CBOs to programmatically deliver similar components of evidence-based interventions as part of state or regional initiatives. 18,19 Within the similar interventions, CBOs may seek opportunities to coordinate their efforts to identify overlap of program activities, collect data, and conduct process and outcome evaluations. ${ }^{13,17}$ More broadly, cross-CBO evaluation efforts can provide evidence of the effectiveness of state-level strategic efforts to use CBOs to support population and public health.

The economic investments being made by private and public funders warrant a deeper understanding of how $\mathrm{CBO}$ s participating in the same intervention can develop the capacity to evaluate intervention implementation efficacy and programmatic outcomes. To better understand the process of building evaluation capacity across multiple CBOs, we use a case study research design to explore and describe the challenges experienced by stakeholders participating in the Ohio Equity Institute's (OEI) building of a statewide $\mathrm{CBO}$ evaluation infrastructure. In subsequent sections, we describe the OEI initiative and the process of building the evaluation infrastructure. The lessons learned from the experience of building the OEI data infrastructure will be helpful for other efforts in Ohio, as well as in those for other states aiming to build robust data collection systems to support CBOs delivering evidence-based interventions.

\section{Background: The Ohio Equity Institute Initiative}

In 2017, Ohio ranked 42nd in the nation for infant mortality, with an infant mortality rate of 7.3 infant deaths per 1000 births..$^{20}$ Moreover, the infant mortality rate in Ohio is almost 3 times as high among Black infants (ie, 14.3 per 1000 births for Black infants compared to 5.1 per 1000 births for White infants in 2019). ${ }^{21}$ Ohio Equity Institute was created to help address these racial disparities in birth outcomes. ${ }^{22}$

Ohio Equity Institute is a collaboration between state agencies, including the Ohio Department of Health (ODH), the Ohio Department of Medicaid (ODM), and the Ohio Department of Higher Education (ODHE), working with local CBOs in the 9 Ohio counties with the largest disparities in infant mortality rates between Black and White infants. In 2018, OEI began to provide funding to 65 CBOs to deliver 3 evidence-based interventions focused on reducing the disparity in infant mortality: CenteringPregnancy group prenatal classes; Home Visiting; or Community Health Workers (CHWs).23-32 The OEI also funded some additional evidence-based interventions including fatherhood programs, community events, a doula program, and a program connecting women to care that did not use CHWs. Services began being provided in August 2018, and by May 31, 2019, CBOs had reached 10074 program participants. Taken together, these interventions were focused on improving the health of pregnant women, infants, and their families within the Ohio counties disproportionately impacted by the disparity in infant mortality.

As a component of OEI, ODM and ODHE cosponsored an evaluation grounded in the collection of participant-level data with the goal of determining the extent to which the selected interventions serve high-risk Medicaid enrolled pregnant women and assessing the effect of these interventions on health care utilization and birth outcomes. This evaluation was proposed in order to build the evidence for the specific impact of the 3 OEI interventions in Ohio, and to allow for the transition from a county-based approach to a participant-based approach to measuring impact.

\section{METHODS}

\section{Building the OEI Data Portal}

To support the OEI evaluation, a team of researchers and technical experts developed and deployed the OEI Data Portal, a data collection system that could be used across all CBOs and was coordinated by a central evaluation team. The OEI Data Portal was built on the Qualtrics web-based software platform ${ }^{33}$ that was extended 
through the development of a custom code base to expand the usability of the system in relation to the tracking and management of participant data by CBOs. The development of the OEI Data Portal proceeded using a 5-step approach: (1) development of a list of appropriate metrics to be collected by the OEI Data Portal based on a literature review and consultation with the OEI stakeholders (ie, ODM, ODH, ODHE); (2) hold initial interviews with CBOs to understand their existing data collection process and technical capacity; (3) draft specifications of the OEI Data Portal based on initial interviews with CBOs; (4) build the OEI Data Portal based on the draft specifications; and (5) provide training sessions to the CBOs on use of the OEI Data Portal.

The initial interviews with the CBOs (ie, Step 2) revealed a range of technological capabilities and resources that the CBOs use to collect data. For instance, some CBOs were collecting data using paper forms, some were using electronic spreadsheets, and others were using more advanced online data entry systems (ie, electronic health records) with data reporting capabilities. Given this variability, the development of the OEI Data Portal involved considering 3 collection modes as a way to provide each CBO the ability to select the data submission format most appropriate for their existing workflow: (1) an online data submission portal that facilitated electronic data submission directly from the CBOs to the OEI Data Portal; (2) paper forms along with mail, fax, scanning, and email options for use by the CBOs; and (3) data submission using common spreadsheet programs (ie, Microsoft Excel).

Five data collection forms were designed to collect data about program participants at 4 time points: Enrollment, Encounter Group encounter (ie, for CenteringPregnancy programs), Birth, and Exit (see Appendix). The Enrollment form is intended to be administered at the first contact between the CBO and the program participant and collects contact information, social security and Medicaid identification number (ID), demographics, gestation at enrollment, prenatal care, housing, transportation, enrollment in social/government programs, and risk factors (ie, low food access, depression, stress, social support, smoking, alcohol use, and drug use). The Encounter forms are designed to be used at all subsequent interactions between the CBO and the participant (or group) and collect the date of the encounter, updates on contact information, and any referrals to additional services. The Birth form is fielded following delivery and reports the infant's name, gender, race, feeding method, and safe sleep practices. The Exit form is completed at the final interaction between the CBO and the program participant, and collects infant well-child care, immunizations, postpartum visits, emergency department visits, father involvement, child care, and updates on housing, employment status, and program enrollment. The OEI Data Portal went live in October 2018 and was designed for CBOs to report data monthly for program participants. As of March 2021, the OEI Data Portal has data on over 120000 participant contacts with the CBOs.

\section{Plan-Do-Study-Act Cycles}

Following the roll out of the OEI Data Portal, the OEI evaluation team engaged in a series of 3 Plan-Do-Study-Act (PDSA) cycles in October 2018 (PDSA Cycle 1), April 2019 (PDSA Cycle 2), and June 2019 (PDSA Cycle 3). ${ }^{34}$ The goal of the PDSA cycles was to identify opportunities to continuously improve the efficiency and quality of data collection and reporting. This process embraces aspects of user-centered design in a codevelopment model where real-time feedback is solicited from end users and communicated to developers of a system. ${ }^{35}$ Below we detail the steps of this evaluation process and then present the key findings.

\section{Data Collection}

All CBOs funded as part of OEI were included in our study sample. After the roll out of the OEI Data Portal, each CBO was invited to a series of 3 key informant semistructured one-on-one and group interviews across the 3-cycle PDSA process to provide information on system optimization. Under the conditions of their funding arrangements, each CBO supplied an administrative contact to the OEI evaluation team. We worked with this administrative contact to identify key informants. Key informants included project managers, program directors, and data administrators.

The goal of PDSA Cycle 1 was to conduct interviews with programs near the beginning of the data collection effort with particular attention to both how they were collecting data and how they were submitting data. This approach served as a quality check for the initial implementation of the system and strengthened engagement between the evaluation team and CBOs. The goal of PDSA Cycles 2 and 3 was to conduct phone interviews with CBO project and data managers to understand the remaining technical issues and identify best practices related to data collection and submission and to interview individuals from programs that were not yet collecting and reporting data at the time PDSA Cycle 1 took place. In PDSA Cycle 3, programs could opt out of participating if they had completed past PDSA calls and did not have any additional input.

All interviews used a semistructured approach that consisted of a series of open-ended questions. Questions were asked about how the organization collects data (eg, "How do you currently collect data about participants in your program?"; "ODM will require agencies receiving funding to collect and report evaluation data about participants to our evaluation team. What would your preferred mode be for sending participant data?"), challenges with data collection (eg, "What are the biggest barriers you face in data collection?"), recommendations to improve the data collection process (eg, "What areas/outcomes do you wish you knew more about or could measure?"), and expectations about program evaluation (eg, "What are you currently doing to evaluate the impact of your program?; What areas/outcomes do you wish you knew more about or could measure?"). Interviews lasted 15 to 45 minutes. This study was approved by The Ohio State University 
institutional review board, and informed consent was obtained for all individuals included in the study.

\section{Data Analysis}

All interviews were recorded but not transcribed, and detailed notes were taken of each interviewee's responses using a memoing approach. ${ }^{36}$ The research team then met weekly to share notes and discuss common themes that emerged in the interviews throughout each PDSA cycle. After development of an initial codebook, the matrix method was applied to categorize the memos and validate our thematic analysis: ${ }^{37-39}$ the interviewers independently organized notes for each theme for each interviewee allowing for data condensation and synthesis across cases. This process is commonly used for rapid-cycle identification of actionable insight, rather than exploration of theoretically deep concepts. ${ }^{40,41}$ This approach was appropriate in this instance to identify common challenges that could be communicated to the developers of the OEI Data Portal to improve the quality of data collection and reporting in a timely manner. Thus, our findings below report on the common or recurring themes from the interviews that were identified in each PDSA cycle, including how the developers resolved each issue.

\section{RESULTS}

A summary of the number of interviews conducted during each PDSA cycle and the number of CBOs represented is provided in Table 1. Some interviewees represented data coordination and submission for multiple CBOs. Of the $65 \mathrm{CBOs}$, those that did not participate in interviews fell into 3 categories: CBOs using a separate system, the Ohio Comprehensive Home Visiting Integrated Data System (OCHIDS), not the OEI Data Portal, for reporting $(\mathrm{n}=12)$; CBOs with business associate agreement/contractual issues preventing data submission $(\mathrm{n}=13)$; and CBOs not collecting or submitting data $(\mathrm{n}=3)$.

\section{Challenges in Data Collection}

Across PDSA cycles, we identified common challenges across the CBOs using the OEI Data Portal and documented the response by the OEI evaluation team to address each specific issue. Challenges were broadly categorized into technical issues (Table 2) and implementation issues (Table 3). We distinguished between these 2 types of issues: those that required changes to the OEI Data Portal itself; and those that required changes to the data submission process, the data collection forms, or the reporting requirements.

\section{Technical Challenges}

The technical challenges often pertained to issues related to the usability of the OEI Data Portal system's data entry component. For instance, CBOs noted that they lacked the ability to update patient contact information, or that they were unable to track their own data entry. These types of issues were addressed by the OEI evaluation team by adding functionality to the OEI Data Portal, as well as making metadata (ie, the date forms were submitted) more accessible to users. Other issues related to the individual's experience of using the OEI Data Portal, such as the speed at which the system operates. These types of issues were resolved by providing the CBOs with additional instruction on use of the OEI Data Portal, such as the internet setting specifications (i.e., preferred browser) that optimize the use of the system.

Implementation Challenges

Implementation challenges were more prevalent in PDSA Cycle 1 than in PDSA Cycles 2 and 3. Broadly, implementation issues pertained to submitting data in formats different from those specified in the OEI data collection forms, not understanding how to answer certain questions, and CBOs not collecting specific variables. Most issues were resolved by changes to the OEI data collection forms or by clarifying reporting needs.

However, a subset of implementation issues was not related to the data portal itself but stemmed from the workflow of the CBOs. For instance, CBOs noted that health literacy issues may be limiting participant responses to questions. Some CBOs described being able to walk through forms with program participants, but not all CBOs had the resources to provide this targeted attention.

Another major issue pertained to the sensitivity of questions. For example, 1 question on the Enrollment form requested the demographic information for the biological father and some participants chose not to provide this information. Similarly, some questions, such as drug use, were viewed as potentially too sensitive. This issue was particularly relevant for the CenteringPregnancy programs where participants might be filling out forms in the presence of individuals seen as authority figures (ie, group facilitators and a doctor) as well as other group members. One approach to addressing these issues was to ask for this information at the second or third encounter with a client, as this would allow an opportunity to develop trust and comfort with the CBO staff.

Participants were similarly concerned about the privacy of the identifiable information that they report (i.e., Medicaid IDs, social security numbers, birthdates, addresses). This issue was particularly prominent for CBOs that served predominantly immigrant populations who may have concerns related to citizenship. The CBOs perceived that these participants had a general distrust for the government and may not necessarily distinguish between ODM and other federal agencies. To address this issue, one CBO requested that a disclaimer be added to the data collection form stating that the information would only be used for quality improvement purposes.

\section{Quality of OEI Data Portal}

By PDSA Cycle 3, most interviewees remarked on their satisfaction with the usability and experience of the OEI Data Portal. We conducted data quality checks throughout the PDSA process to identify the percent of missing or erroneous data from each $\mathrm{CBO}$ and to track the number of CBOs reporting data. Initially, $52 \%$ of data 
Table 1. Categories Summary of Plan-Do-Study-Act (PDSA) Interviews and Representation of Community-Based Organizations (CBOs)

\begin{tabular}{|lll|}
\hline PDSA Cycle & Number of interviews & Number of CBOs represented \\
PDSA Cycle 1 & 12 & 20 \\
PDSA Cycle 2 & 18 & 38 \\
PDSA Cycle 3 & 13 & 31 \\
\hline
\end{tabular}

\section{Table 2. Technical Challenges and Solutions with Developing the OEI Data Portal}

PDSA Cycle 1 Challenges

Inability to change participant

contact information

Inability to upload multiple data forms

Lag time in the data portal

Inconsistent question order in different submission formats

Usability of encounter data collection form

\section{Challenge}

\section{Description}

$\mathrm{CBO}$ s were unable to make changes to contact information for participants once they were added to the portal.

The ability to place multiple data forms in the submission field, instead of placing them 1 at a time, was requested.

Forms that were added or completed would not update immediately in the OEI Data Portal.

The Excel spreadsheet questions did not follow the same orderas the surveys on Qualtrics.

The Encounter form was perceived as too intimidating and was not optimized for use by participants themselves.

\section{PDSA Cycle 2 Challenges}

Unable to track data entry

$\mathrm{CBO}$ s could not see when they last entered data.

Deletion of historical records from view

PDSA Cycle 3 Challenges

Unable to correct data entry errors

Confusing visual display

No process for exiting some patients

Missing answer choices for gender

Data entry limitations
The OEI Data Portal deletes a participant's name when they exit the program. The CBOs did not like the inability to access forms for people who have exited, foreseeing a potential need to update information for participants.

Cannot unselect answer response if wrong choice is chosen

Text boxes do not align with data entry boxes.

No way to complete exit form for patients that do not have postpartum visit

No nonbinary options (eg, trans) on forms, nor a

Limit on amount of group encounters that can be submitted requires using multiple sheets 'Not Applicable' option for male participants

\section{Resolution}

A link was added to each participant's name that allows updates to contact information.

Three fields that can each accept 1 file were added, as Qualtrics does not allow fields that accept multiple simultaneous uploads.

CBOs were provided instructions about the ideal internet settings to use Qualtrics effectively. The programs notified us that speed improved.

The Excel spreadsheet was modified so questions were in a consistent order with the Qualtrics survey.

A new Encounter form template was created with the same questions but a new format, designed to look like a sign-in sheet, and with questions worded to request information directly from the participant rather than from CBO staff.

The date a form was submitted to the OEI Data Portal was added in place of the word "Complete" for the Enrollment Birth, and Encounter forms.

Participants that have exited the program now appear in a separate table, and their data can be edited.

Surveys were altered to allow response changes throughout.

Visual alterations were completed to better align data entry boxes on forms.

Enter known data and we can match outcome data using other data sources

When gender is unknown, the question can be skipped $\mathrm{CBO}$ staff encouraged to ask the question to the participant and write down the gender the participant calls themselves.

More data entry lines for participants were added to Group encounter form in portal.

Notes: OEI = Ohio Equity Institute; PDSA = Plan-Do-Study-Act; $C B O=$ community-based organization; CHW = community health worker. 
Table 3. Implementation Challenges and Solutions with Developing the OEI Data Portal

\begin{tabular}{|c|c|c|}
\hline Challenge & Description & Resolution \\
\hline \multicolumn{3}{|l|}{ PDSA Cycle 1 Challenges } \\
\hline $\begin{array}{l}\text { Non-applicable } \\
\text { questions }\end{array}$ & $\begin{array}{l}\text { Concerns were raised about the fact that certain questions, such } \\
\text { as home safety issues, do not always apply, so the question is left } \\
\text { incomplete. }\end{array}$ & $\begin{array}{l}\text { Added "none of the above apply" response } \\
\text { option. }\end{array}$ \\
\hline Missing data & $\begin{array}{l}\text { In some cases, participants were not enrolled in Medicaid and } \\
\text { therefore did not have a Medicaid identification number. }\end{array}$ & $\begin{array}{l}\text { Instruction was included to leave the } \\
\text { Medicaid identification field blank, rather } \\
\text { than entering insurance identifiers for other } \\
\text { insurance types. }\end{array}$ \\
\hline Structural issues & $\begin{array}{l}\text { A few programs - specifically, those that have } \mathrm{CHWs} \text { completing } \\
\text { care coordination and service connection tasks - provide services } \\
\text { to people who are not either pregnant or recent parents. }\end{array}$ & $\begin{array}{l}\text { A question was added to an updated } \\
\text { Encounter form assessing whether the } \\
\text { participant was pregnant or was a parent of } \\
\text { an infant. }\end{array}$ \\
\hline $\begin{array}{l}\text { Incomplete legacy data } \\
\text { collection systems }\end{array}$ & $\begin{array}{l}\text { Many CBOs use the Care Coordination System }(C C S)^{a} \text { to collect } \\
\text { data, export this data to a spreadsheet, and submit it. }\end{array}$ & $\begin{array}{l}\text { The CBOs were asked to export all CCS } \\
\text { variables instead of only a subset so the } \\
\text { maximum amount of data can be used for } \\
\text { the OEl evaluation. }\end{array}$ \\
\hline $\begin{array}{l}\text { Data collection } \\
\text { inconsistent with } \\
\text { workflow }\end{array}$ & $\begin{array}{l}\text { Some programs, especially CHW programs, only see clients once } \\
\text { and do not collect detailed demographic data, as their encounters } \\
\text { are designed to quickly connect people to community resources. }\end{array}$ & $\begin{array}{l}\text { A modified Encounter form with more } \\
\text { data fields was provided to collect limited } \\
\text { demographic information (eg, race, } \\
\text { employment, and marital status) better } \\
\text { suited to brief interactions. }\end{array}$ \\
\hline Health literacy & $\begin{array}{l}\text { Participant health literacy may limit ability to understand and } \\
\text { answer questions on intake forms. }\end{array}$ & $\begin{array}{l}\text { The CBOs were asked to assist participants } \\
\text { in answering questions on forms and ex- } \\
\text { plain questions that may not be understood. }\end{array}$ \\
\hline \multicolumn{3}{|l|}{ PDSA Cycle 3 Challenges } \\
\hline $\begin{array}{l}\text { Reluctance to provide } \\
\text { answer to sensitive } \\
\text { question }\end{array}$ & $\begin{array}{l}\text { Participant hesitant to answer questions due to concerns about } \\
\text { loss of benefits and services. }\end{array}$ & $\begin{array}{l}\text { The CBOs were asked to collect this } \\
\text { information on second or third visit to allow } \\
\text { for greater trust, comfort and familiarity } \\
\text { with CBO. }\end{array}$ \\
\hline
\end{tabular}

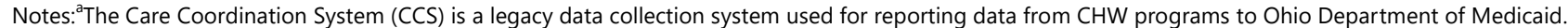
$\mathrm{OEI}=$ Ohio Equity Institute; PDSA = Plan-Do-Study-Act; $\mathrm{CBO}=$ community-based organization; $\mathrm{CHW}=$ community health worker.

fields were complete and 33 CBOs reported data, but by the end of PDSA Cycle 3 this metric had improved to $55 \%$ of data fields complete for 58 CBOs. Thus, while the percent of complete data increased only slightly, the number of CBOs capable of reporting data increased substantially.

\section{DISCUSSION}

Community-based organizations are increasingly important providers of health education and can expand the capacity of health care organizations and government agencies to address social determinants of health. These agencies provide a wealth of services to communities, yet, given their funding structures, they frequently lack the resources to develop robust data collection and evaluation infrastructures. To this end, we developed the OEI
Data Portal to evaluate 3 evidence-based interventions aimed at reducing disparities in infant mortality across the state of Ohio. Our PDSA process was able to identify, document, and redress several technical and implementation challenges in order to support data reporting. This case study provides insight for other efforts that seek to capture data across CBOs providing similar interventions for evaluation purposes.

\section{Importance of Building Relationships}

Our PDSA cycles highlight the need for ongoing relationships with CBOs in order to understand both their technical capacities and workflows in order to ensure high-quality data collection. For instance, many of the initial technical challenges that were identified related to a lack of familiarity of the OEI evaluation team with 
the specific needs and experiences of the CBOs, and they were resolved through engagement between the $\mathrm{CBO}$ s and the evaluation team. Similarly, the implementation challenges often resulted from a mismatch between the data collection forms and data entry process with the actual workflows of the CBOs. The ongoing communication and relationship between the OEI evaluation team and the CBOs facilitated by the PDSA process helped to identify and resolve these issues.

Engaging with the CBOs further required responding to their data submission preferences. A strength of the OEI Data Portal is its flexibility in this regard, as we offered a number of technologies to collect data: direct data entry, paper forms and fax, and data uploads of extracted files from other systems. While the preference for the majority of CBOs was direct data entry via the OEI Data Portal, CBOs affiliated with health care organizations preferred to deliver data via the upload of a data file.

These engagement efforts resolved immediate challenges CBOs reported with providing data to a common system, but also resulted in more complete and accurate data collection. The experience of having their data collection and entry needs met, and seeing more complete and accurate data through the development of the data collection system, can increase CBOs' trust in the evaluation team and process, which is critical in successful community-based efforts. ${ }^{42,43}$

\section{Augmenting CBO-Provided Data}

While CBO-provided data allowed us to understand participation in the 3 evidence-based interventions examined, both ODM and the CBOs seek to evaluate the impact of participation in the OEI interventions on infant mortality and low birth weight. This analysis requires matching information about patient use of the OEI interventions from the OEI Data Portal to information about birth outcomes and deaths from the state vital statistics records. Adding complexity to this issue is that some CBOs, such as the home visiting programs, submit data to OCHIDS, a separate and distinct system from the OEI Data Portal created by ODH to collect data from selected home visiting programs. The need to match data from the OEI Data Portal with other sources underscores the necessity of building a reliable data collection system. As programs such as Partnership for Healthy Outcomes ${ }^{7}$ and the Robert Wood Johnson Foundation's Culture of Health ${ }^{8}$ expand collaborations between CBOs and health care organizations, leveraging existing data collection and stakeholder-informed data collection such as our OEI Data Portal can facilitate a more comprehensive evaluation process.

Moving forward, state sponsors of CBOs may consider efforts to integrate data collection systems across multiple projects. Many existing state-based efforts to coordinate the exchange of health information across the state rely on community health information exchanges (HIEs) or regional health information organizations. However, HIEs are typically designed to facilitate exchange of health information between health care providers and are not optimized to the needs of CBOs. Further, HIEs are rarely oriented toward evaluation. ${ }^{44}$ Nonetheless, leveraging the existing HIE infrastructure may offer states a potential shortcut to creating repositories of CBO data. The lessons we report in this case study of the OEI Data Portal could help in any efforts to adapt HIE platforms to the needs of CBOs.

\section{Limitations}

This study is subject to some important limitations. First, all the CBOs funded by OEI were selected in part due to their willingness to submit required data, potentially resulting in a sample of CBOs more prone toward accommodating reporting and evaluation requests. Second, the OEI experience may be specific to the state of Ohio, and, as a result, our findings may not be generalizable in different states with different regulatory and funding structures. Building a robust evaluation infrastructure and capturing highquality data is a necessary first step prior to conducting any outcome evaluation. Future work will focus on evaluating the impact of the interventions on the specific outcomes of interest-infant mortality and low birth weight.

\section{PUBLIC HEALTH IMPLICATIONS}

Infant mortality is a complex problem impacting communities in Ohio, and multiple programs have been developed to reduce the risk of poor infant and maternal outcomes. Due to varying program designs, levels of data collection, and small program sizes, it is hard to assess the impact of individual programs on outcomes. The OEI can serve as a model for data collection from many similar CBO delivered programs across the state to enable evaluation of these efforts. Individual CBOs experienced technical and implementation challenges when starting to use the new data collection system. However, building relationships between CBOs and the evaluation team and providing training resulted in improved data quality and increased the number of organizations reporting data over the first year of data collection system implementation.

\section{ACKNOWLEDGMENTS}

The authors have no relevant financial or nonfinancial conflicts of interest to disclose. This project was supported by a contract from the Ohio Department of Medicaid. The content is solely the responsibility of the authors and does not necessarily represent the official views of the sponsor.

\section{REFERENCES}

1. Barton-Villagrana H, Bedney BJ, Miller RL. Peer relationships among community-based organizations (CBO) providing HIV prevention services. J Prim Prev. 2002;23(2):215-234. https://doi.org/10.1023/A:1019920400029

2. Blas E, Gilson L, Kelly MP, et al. Addressing social determinants of health inequities: what can the state and civil society do? Lancet. 2008;372(9650):1684-1689. https://doi.org/10.1016/S0140-6736(08)61693-1

3. Wilson MG, Lavis JN, Guta A. Community-based organizations in the health sector: a scoping review. Health Res Policy Syst. 2012;10:36. https://doi.org/10.1186/1478-4505-10-36 
4. Wallerstein N, Duran B. Community-based participatory research contributions to intervention research: the intersection of science and practice to improve health equity. Am J Public Health. 2010;100 Suppl 1:S40-46. https://doi.org/10.2105/AJPH.2009.184036

5. Akintobi TH, Yancey EM, Daniels P, Mayberry RM, Jacobs D, Berry J. Using evaluability assessment and evaluation capacity-building to strengthen community-based prevention initiatives. J Health Care Poor Underserved. 2012;23(2 Suppl):33-48. https://doi.org/10.1353/hpu.2012.0077

6. Cacari-Stone L, Wallerstein N, Garcia AP, Minkler M. The promise of community-based participatory research for health equity: a conceptual model for bridging evidence with policy. Am J Public Health. 2014;104(9):1615-1623 https://doi.org/10.2105/AJPH.2014.301961

7. Partnership for Healthy Outcomes. Using Medicaid Levers To Support Health Care Partnerships With Community-Based Organizations. 2017. Accessed March 15, 2021. https://www.chcs.org/media/CBO-HCO-Partnership-Medicaid-FactSheet_102417_chcs.pdf

8. Robert Wood Johnson Foundation. Building a Culture of Health. 2021 Accessed March 16, 2021 https://www.rwjf.org/en/how-we-work/building-a-culture-ofhealth.html

9. Taylor LA, Byhoff E. Money moves the mare: the response of community-based organizations to health care's embrace of social determinants. Milbank Q. 2021; 99(1): 71-208. https://doi.org/10.1111/1468-0009.12491

10. Adebayo OW, Salerno JP, Francillon V, Williams JR. A systematic review of components of community-based organisation engagement. Health Soc Care Community. 2018;26(4):e474-e484. https://doi.org/10.1111/hsc.12533

11. Likumahuwa S, Song H, Singal R, et al. Building research infrastructure in community health centers: a community health applied research network (CHARN) report. J Am Board Fam Med. 2013;26(5):579-587. https://doi.org/10.3122/jabfm.2013.05.130025

12. Mayberry RM, Daniels P, Akintobi TH, Yancey EM, Berry J, Clark N. Community-based organizations' capacity to plan, implement, and evaluate success. J Community Health. 2008;33(5):285-292. https://doi.org/10.1007/s10900-008-9102-z

13. Kegeles SM, Rebchook GM. Challenges and facilitators to building program evaluation capacity among community-based organizations. AIDS Educ Prev. 2005;17(4):284-299. https://doi.org/10.1521/aeap.2005.17.4.284

14. Norton S, Milat A, Edwards B, Giffin M. Narrative review of strategies by organizations for building evaluation capacity. Eval Program Plann. 2016;58:1-19.

https://doi.org/10.1016/j.evalprogplan.2016.04.004

15. Preskill H, Boyle S. A multidisciplinary model of evaluation capacity building. Am JI Eval. 2008;29(4):443-459. https://doi.org/10.1177/1098214008324182

16. Stevenson JF, Florin P, Mills DS, Andrade M. Building evaluation capacity in human service organizations: a case study. Eval Program Plann. 2002;25(3):233-243. https://doi.org/10.1016/S0149-7189(02)00018-6
17. Wandersman A, Chien VH, Katz J. Toward an evidence-based system for innovation support for implementing innovations with quality: tools, training, technical assistance, and quality assurance/quality improvement. Am J Community Psychol. 2012;50(3-4):445-459. https://doi.org/10.1007/s10464-012-9509-7

18. Burd C, Gruss S, Albright A, Zina A, Schumacher P, Alley D. Translating knowledge into action to prevent type 2 diabetes: medicare expansion of the national diabetes prevention program lifestyle intervention. Milbank Q. 2020;98(1):172-196. https://doi.org/10.1111/1468-0009.12443

19. Willging CE, Gunderson L, Green AE, et al. Perspectives from community-based organizational managers on implementing and sustaining evidence-based interventions in child welfare. Hum Serv Organ Manag Leadersh Gov. 2018;42(4):359-379. https://doi.org/10.1080/23303131.2018.1495673

20. Rankings AsH. National Infant Mortality. 2020. Accessed March 16, 2021.

https://www.americashealthrankings.org/explore/health-of-womenand-children/measure/IMR_MCH

21. Ohio Department of Health. 2019 Infant Mortality Report. 2019. Accessed March 16, 2021.

https://odh.ohio.gov/wps/portal/gov/odh/know-our-programs/ infant-and-fetal-mortality/reports/2019-ohio-infant-mortality-report

22. Ohio Department of Health. Ohio Equity Institute. 2020. Accessed March 16, 2021.

https://odh.ohio.gov/wps/portal/gov/odh/know-our-programs/ maternal-infant-wellness/oei

23. Aboubaker S, Qazi S, Wolfheim C, Oyegoke A, Bahl R. Community health workers: a crucial role in newborn health care and survival. J Glob Health. 2014;4(2):020302. https://doi.org/10.7189/jogh.04.020302

24. Becker J, Kovach AC, Gronseth DL. Individual empowerment: how community health workers operationalize self-determination, selfsufficiency, and decision-making abilities of low-income mothers. J Community Psychol. 2004;32(3):327-342. https://doi.org/10.1002/jcop.20000

25. Hollowell J, Oakley L, Kurinczuk JJ, Brocklehurst P, Gray R. The effectiveness of antenatal care programmes to reduce infant mortality and preterm birth in socially disadvantaged and vulnerable women in highincome countries: a systematic review. BMC Pregnancy Childbirth. 2011;11:13 https://doi.org/10.1186/1471-2393-11-13

26. Issel LM, Forrestal SG, Slaughter J, Wiencrot A, Handler A. A review of prenatal home-visiting effectiveness for improving birth outcomes. $J$ Obstet Gynecol Neonatal Nurs. 2011;40(2):157-165. https://doi.org/10.1111/j.1552-6909.2011.01219.x

27. Jack S, DiCenso A, Lohfeld L. Opening Doors: Factors influencing the establishment of a working relationship between paraprofessional home visitors and at-risk families. CJNR. 2002;34(4):59-69.

28. Olds DL, Kitzman H. Can home visitation improve the health of women and children at environmental risk. Pediatrics. 1990;86(1):108-116.

29. Peacock S, Konrad S, Watson E, Nickel D, Muhajarine N. Effectiveness of home visiting programs on child outcomes: a systematic review. $B M C$ Public Health. 2013;13:17. https://doi.org/10.1186/1471-2458-13-17 
30. Swoboda CM, Benedict JA, Hade E, McAlearney AS, Huerta TR. Effectiveness of an infant mortality prevention home-visiting program on high-risk births in Ohio. Public Health Nurs. 2018;35(6):551-557. https://doi.org/10.1111/phn.12544

31. Swoboda CM, McAlearney AS, Huerta TR. Risk factors among participants in a community health worker led infant mortality prevention home-visiting program. Journal of Community and Preventive Medicine. 2018;1(1):1-7.

32. Thielen K. Exploring the group prenatal care model: a critical review of the literature. J Perinat Educ. 2012;21(4):209-218.

https://doi.org/10.1891/1058-1243.21.4.209

33. Qualtrics, [computer program]. Provo, UT.2020.

34. Institute for Healthcare Improvement. How to Improve. 2021. Accessed March 19, 2021.

http://www.ihi.org/resources/Pages/HowtoImprove/default.aspx

35. Abras C, Maloney-Krichmar D, Preece J. User-centered design. Bainbridge, W Encyclopedia of Human-Computer Interaction Thousand Oaks: Sage Publications. 2004;37(4):445-456.

36. Birks M, Chapman Y, Francis K. Memoing in qualitative research: probing data and processes. J Res Nurs. 2008;13(1):68-75. https://doi.org/10.1177/1744987107081254

37. Averill JB. Matrix analysis as a complementary analytic strategy in qualitative inquiry. Qual Health Res. 2002;12(6):855-866. https://doi.org/10.1177/104973230201200611

38. Groenland E. Employing the matrix method as a tool for the analysis of qualitative research data in the business domain. Int J Bus Glob. 2018;21(1):119-134. https://doi.org/10.2139/ssrn.2495330

39. Lewinski AA, Crowley MJ, Miller C, et al. Applied rapid qualitative analysis to develop a contextually appropriate intervention and increase the likelihood of uptake. Med Care. 2021;59:S242-S251. https://doi.org/10.1097/MLR.0000000000001553

40. Gale RC, Wu J, Erhardt T, et al. Comparison of rapid vs in-depth qualitative analytic methods from a process evaluation of academic detailing in the veterans health administration. Implement Sci. 2019;14(1):1-12. https://doi.org/10.1186/s13012-019-0853-y

41. Taylor B, Henshall C, Kenyon S, Litchfield I, Greenfield S. Can rapid approaches to qualitative analysis deliver timely, valid findings to clinical leaders? a mixed methods study comparing rapid and thematic analysis. BMJ open. 2018;8(10):e019993.

https://doi.org/10.1136/bmjopen-2017-019993

42. Stout SS, Simpson LA, Singh P. Trust between health care and community organizations. JAMA. 2019;322(2):109-110. https://doi.org/10.1001/jama.2019.1211

43. Amarasingham R, Xie B, Karam A, Nguyen N, Kapoor B. Using community partnerships to integrate health and social services for high-need, high-cost patients. 2018. Accessed March 16, 2021.

https://www.commonwealthfund.org/publications/issuebriefs/2018/jan/using-community-partnerships-integrate-health-andsocial

44. Yeager VA, Vest JR, Walker D, Diana ML, Menachemi N. Challenges to conducting health information exchange research and evaluation: reflections and recommendations for examining the value of HIE. EGEMS (Wash DC). 2017;5(1):15. https://doi.org/10.5334/egems.217 


\section{APPENDIX. Data Collection Forms}

Ohio Department of Medicaid
The OHIo STATE UNIVERSITY

COLLEGE OF MEDICINE

\section{OhioHigherEd}

\section{Enrollment form}

Complete this form when a participant enrolls in the program.

Please write clearly in blue or black ink, place only one character in each box, and use all uppercase letters; this form will be read by a computer.

(1) On what date did the participant enroll in the program?

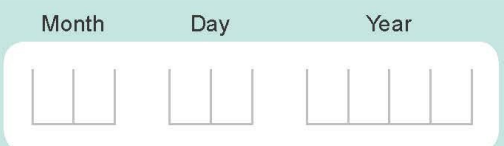

(2) What is the participant's birth date?

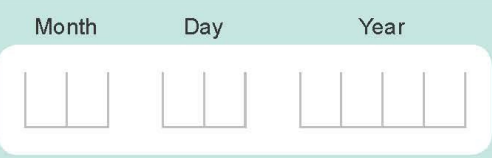

(3) Participant's identification information:

First name

Last name
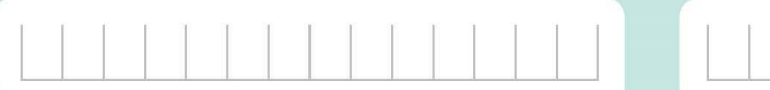

Social Security number

Medicaid ID number

Gender
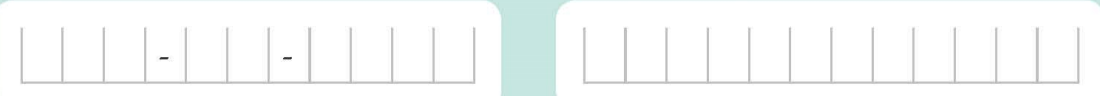

Female

Street address

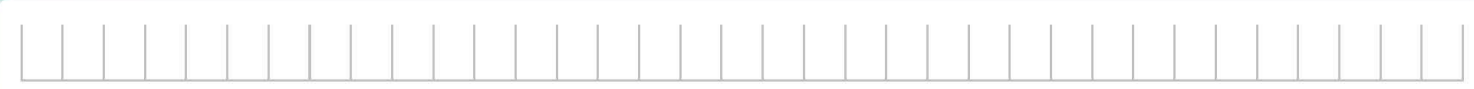

City

ZIP code

Phone number

(4) How did the participant learn about this program?

(5) Participant's employment status (please check all that apply):

Friend or family member

Medical provider

Other prenatal or infant care program

Social/governmental program

Advertisements in the community

Other (please specify)

Employed full time

Employed part time

Unemployed, receiving assistance

Unemployed, not receiving assistance

Enrolled in school

Disabled 


\section{Enrollment}

\section{Month}
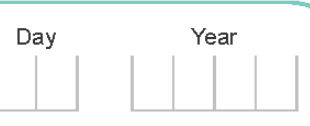

Page 2 of 4

(6)

Participant's marital status:

$\square \quad$ Married
$\square \quad$ Widowed
$\square \quad$ Divorced
$\square \quad$ Separated
$\square \quad$ Single/never married
$\square \quad$ Not married but living with partner

(7) Current relationship between participant and other biological parent:

$\square \quad$ Married
$\square \quad$ Widowed
$\square \quad$ Divorced
$\square \quad$ Separated
$\square \quad$ Never married

(8) Living status between participant and other biological parent:

$(\square)$ Living together $\square$ Not living together

If you marked living together, you may skip the address fields in the section at the bottom of this page. If not, complete these fields.

(9) Other biological parent's birth date:

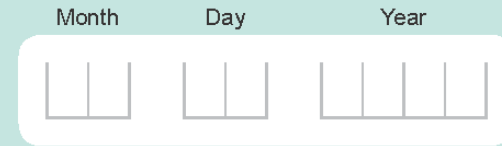

(10)

Participant's race/ethnicity (please check all that apply):

$\square$ White
$\square \quad$ Black or African American
$\square \quad$ Hispanic or Latino
$\square \quad$ Asian
$\square \quad$ Native Hawaiian or Pacific Islander
$\square \quad$ American Indian or Alaska Native
$\square \quad$ Other (please specify)

Other biological parent's race/ethnicity (please check all that apply):

$\square$ White
$\square \quad$ Black or African American
$\square \quad$ Hispanic or Latino
$\square \quad$ Asian
$\square \quad$ Native Hawaiian or Pacific Islander
$\square \quad$ American Indian or Alaska Native
$\square \quad$ Other (please specify)

(12)

Other biological parent's identification information:

First name

Last name
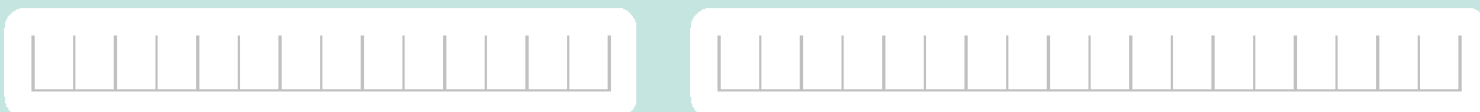

Street address

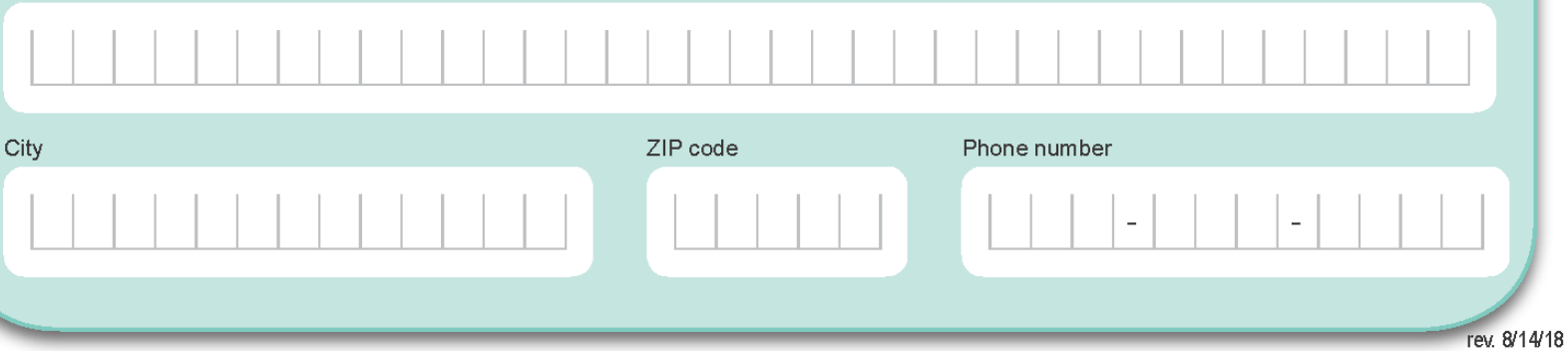


13. How many total adults live in the same household as the participant (including the participant)?

14. How many total children live in the same household as the participant?

15 What kind of housing does the participant have?

$\square$ Live in house/apartment owned by participant
$\square$ Live in house/apartment owned by family/friends
$\square \quad$ Live in rented house/apartment
$\square \quad$ Live in shelter or group home
$\square \quad$ Public housing
$\square \quad$ Homeless
$\square$ Other (please specify)

16.

Please check any home safety issues the participant is experiencing.

No working smoke detectors

Firearms or weapons in home

Smell of gas/mildew/mold

Pests suspected/present

Smoking in house

Windows/doors do not lock appropriately

Garbage/clutter/unclean environment

Drugs/chemicals/cleaning supplies within reach

(17)

Participant's primary method of transportation:

Own car

Bus

Taxi

Walk

Friend's/family car

Other (please specify)
(18)

Is the participant currently enrolled in any of the following public assistance programs? (Please check all that apply.)

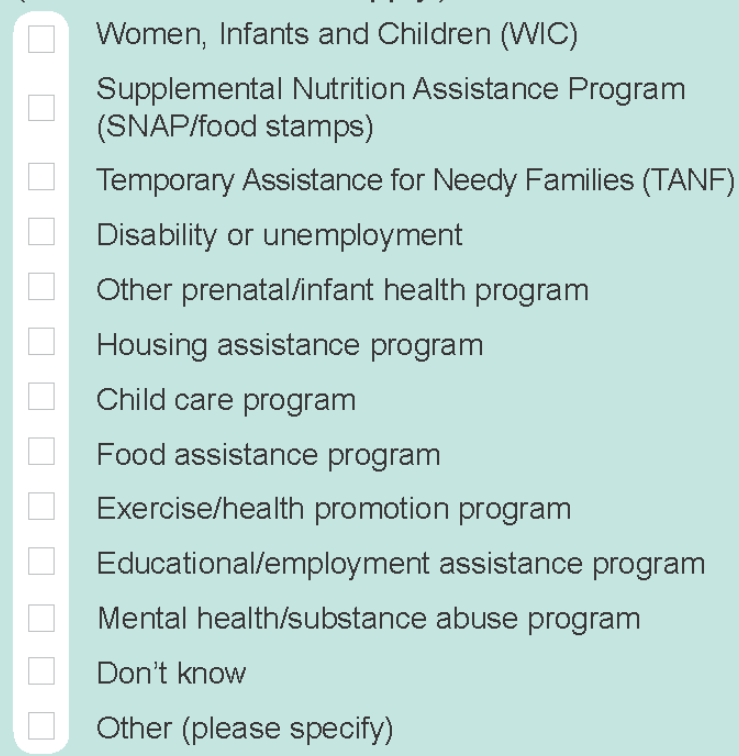

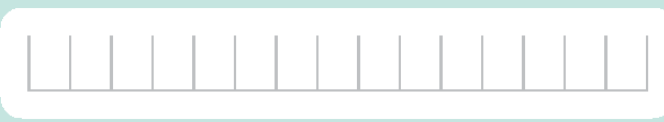

(19)

Is the participant financially stable (able to pay their bills without any monetary aid or help)?

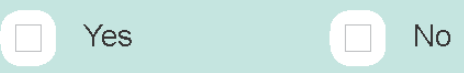

Does the participant have access to adequate food?

$\square$ Yes $\square$ No

Does the participant have current depression or a history of depression diagnosis or treatment?

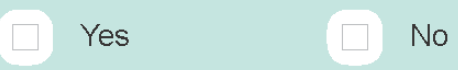

In the past month, did the participant feel they could not control important things in their life?<smiles></smiles>

(23)

Is there at least one person the participant can discuss their thoughts and feelings with?

$\square$ Yes $\square$ No 
Enrollment Participant's last name and birth date Month Day

24. Does the participant or anyone in their household smoke? (If no, skip to \#27.)

The participant smokes but nobody else in the household smokes

At least one member of the household smokes but the participant does not Both the participant and at least one other person in the household smoke

No one in the household smokes

(25) If the participant smokes, number of cigarettes smoked per day:

\section{(26)}

If others in the household smoke, number of cigarettes smoked per day:

\begin{tabular}{|c|}
\hline $\begin{array}{l}\text { Less than one } \\
\text { per day }\end{array}$ \\
\hline $1-5$ \\
\hline $6-10$ \\
\hline $11-15$ \\
\hline $16-20$ \\
\hline $\begin{array}{l}\text { More than } 20 \\
\text { per day }\end{array}$ \\
\hline
\end{tabular}

16-20

More than 20 per day
(27) In the past month, has the participant drank any alcohol?

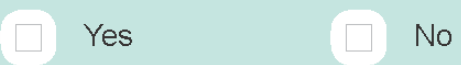

(28) In the past six months, has the participant used any illegal substances? (If no, skip to \#30.)<smiles></smiles>

(29) If yes to \#28, how frequently does the participant use controlled substances?
$\square$ More than once per day
Once per day
A few times per week or less
A few times per month or less
Only on occasion; less than once per month

(30)

Do any of the participant's friends or family members have problems with alcohol or other drug use?

The final six questions on this form do not apply to participants in a fatherhood program.

(31) Participant's weeks of gestation at enrollment in the program:

Infant has already been born

(32) How many prenatal care visits has the participant had prior to enrollment?

33 Did the participant have any prenatal visits in her first trimester (weeks 1-12)?

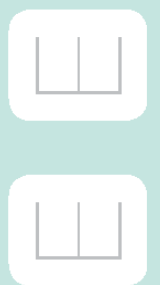

34 Has the participant received treatment with progesterone during this pregnancy?

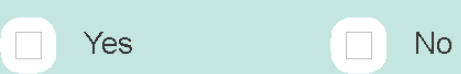

35 Does the participant take folic acid/vitamins?<smiles>CC(C)(C)c1ccccc1</smiles>

36 Is transportation a barrier to the participant attending prenatal care appointments?

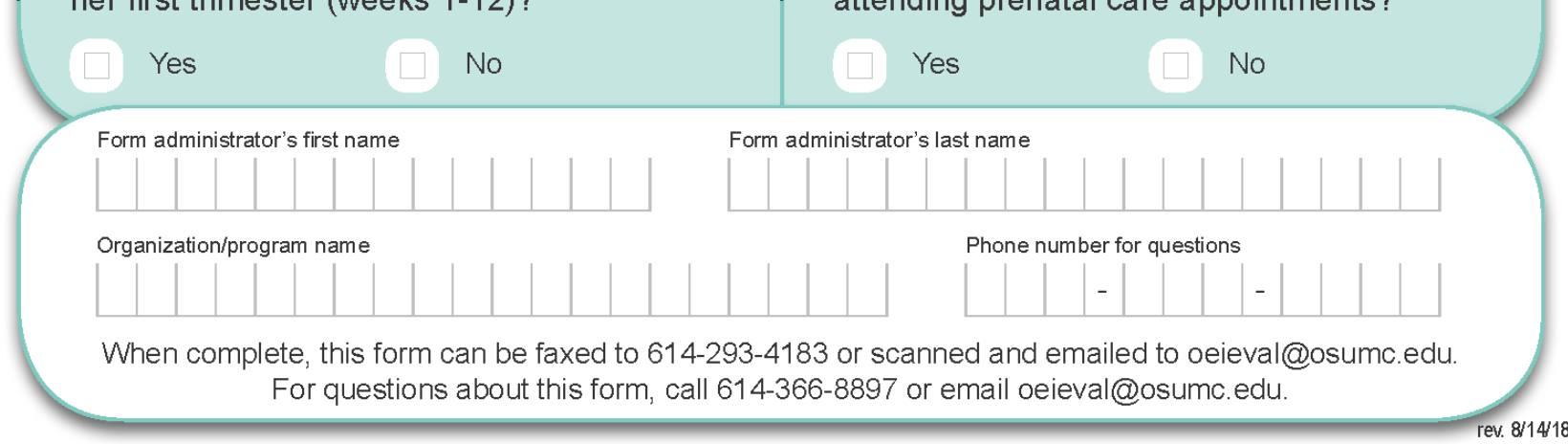




\section{Ohio \\ Department of Medicaid \\ THE OHIO STATE UNIVERSITY \\ COLLEGE OF MEDICINE \\ OhioHigherEd}

\section{Encounter form}

Complete this form when an encounter with a participant takes place.

Please write clearly in blue or black ink, place only one character in each box, and use all uppercase letters; this form will be read by a computer.

(1) On what date did this encounter occur?

(2) What is the participant's birth date?
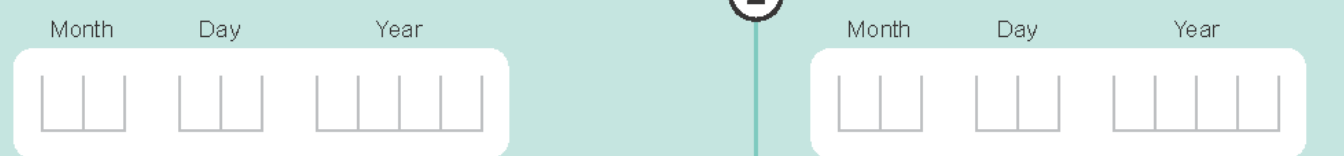

(3) Participant's identification information:

First name

Last name

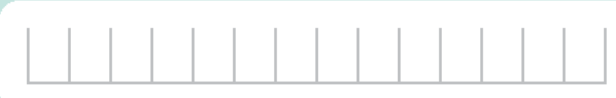

Street address

Gender

(n)

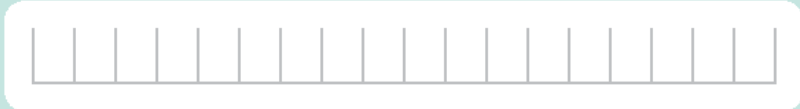

$\square$ Female

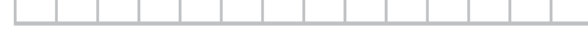

City

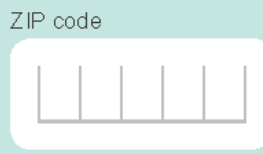

Phone number
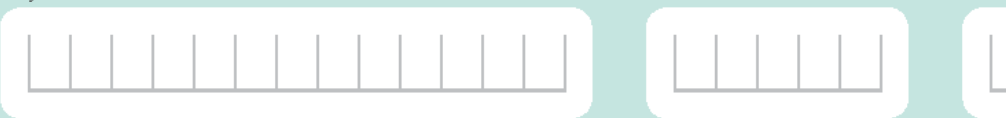

(4)

What is the next planned contact date?

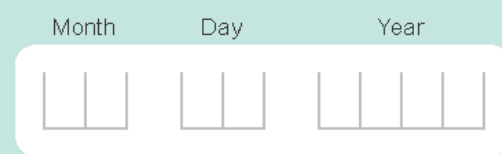

(6) If yes to \#5, please list any additional programs or services the participant was referred to.

(5) Was the participant referred to any additional programs or services?

$\square$ Yes $\square$ No

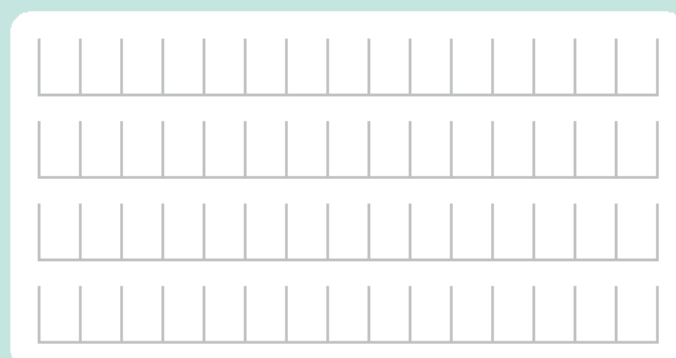

Form administrator's first name

Form administrator's last name

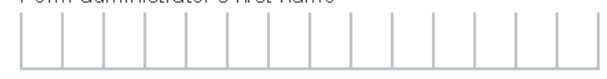

$+|+|+\mid$

Organization/program name

$\stackrel{\text { Organization/ }}{\mid}$

When complete, this form can be faxed to 614-293-4183 or scanned and emailed to oeieval@osumc.edu.

For questions about this form, call 614-366-8897 or email oeieval@osumc.edu.

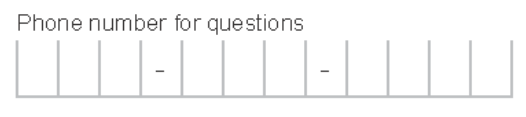




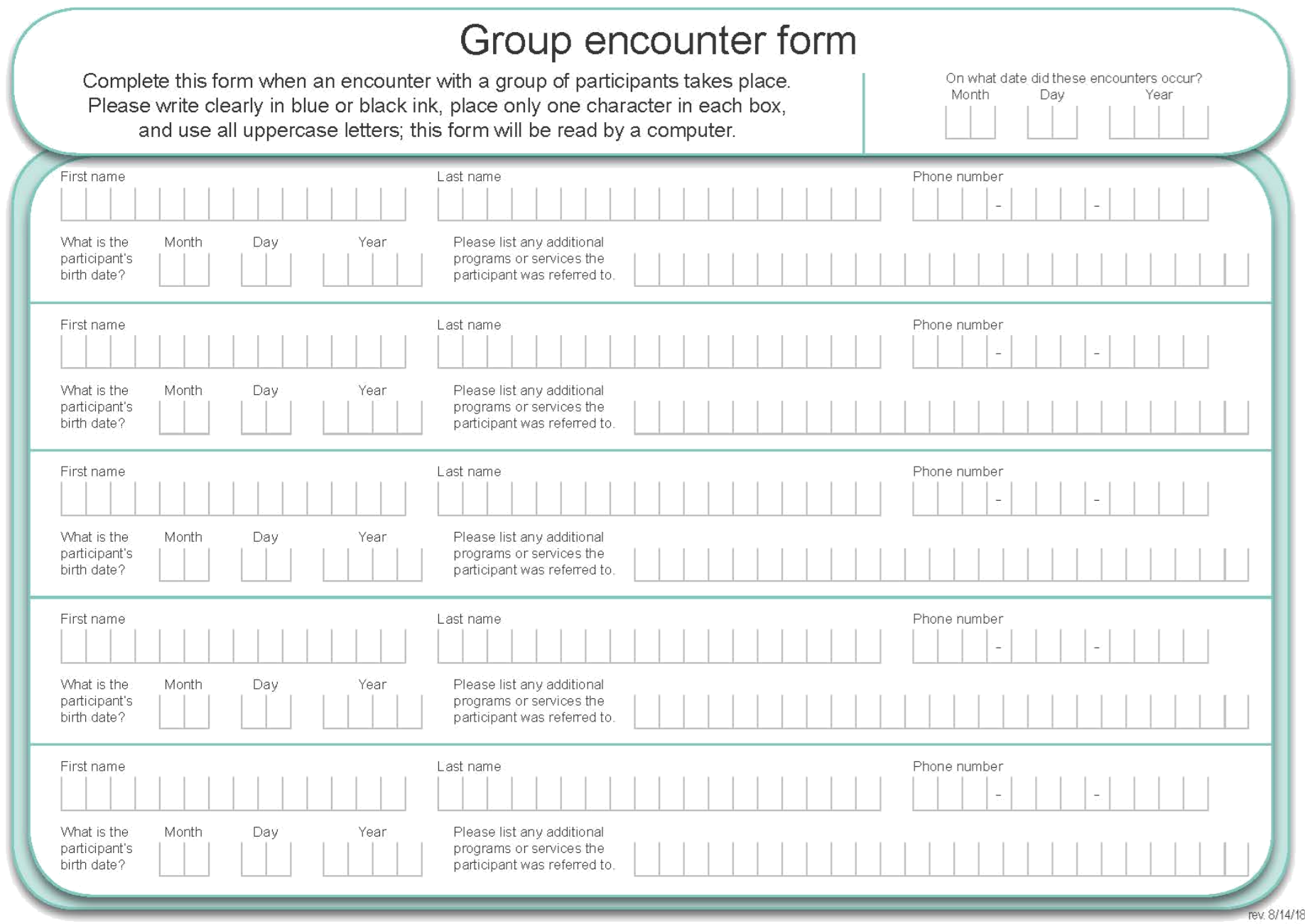




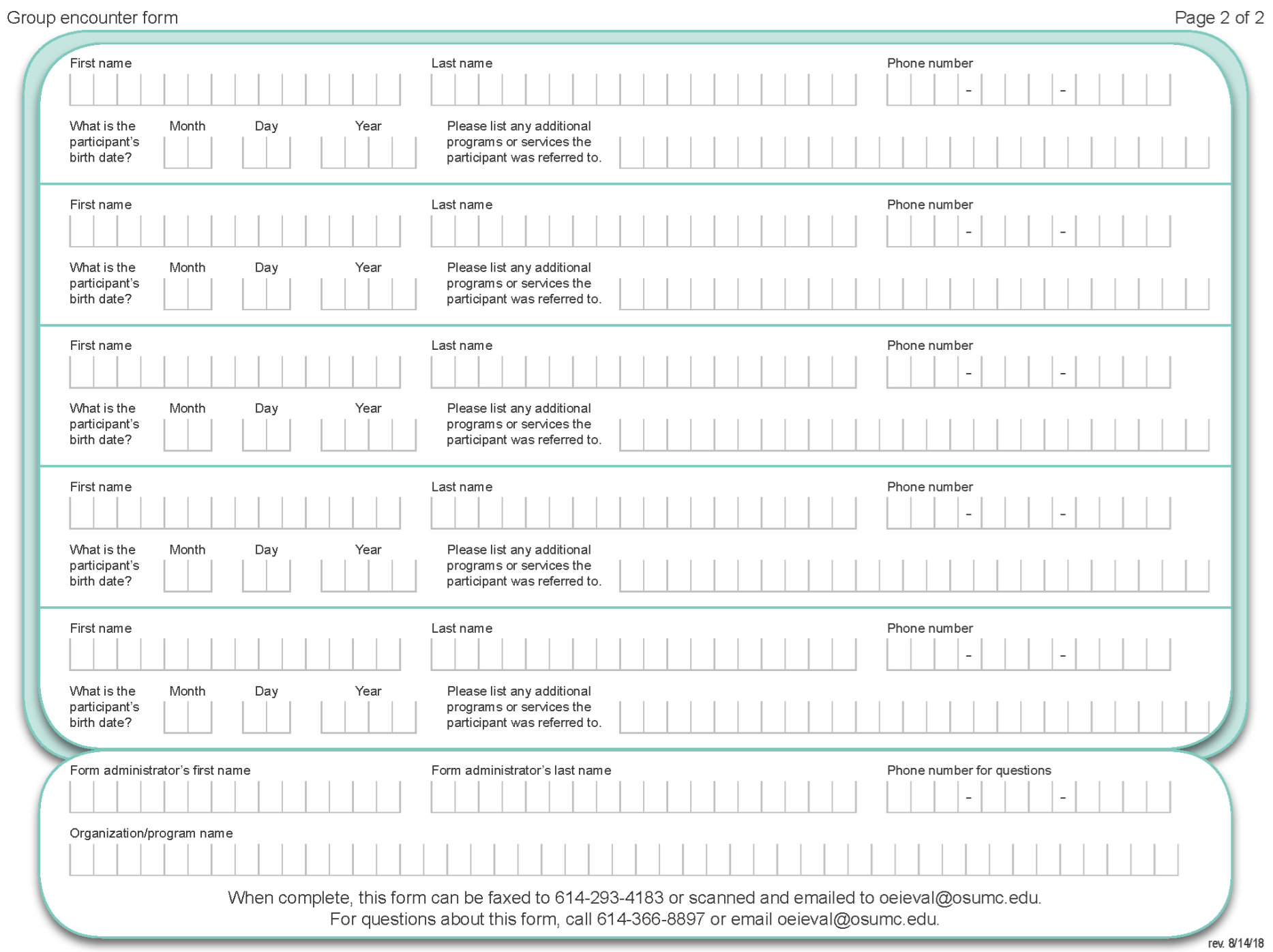


Ohio

Department of Medicaid

THE OHIO STATE UNIVERSITY

COLLEGE OF MEDICINE

\section{OhioHigherEd}

\section{Birth form}

Complete this form the first time data is collected after the birth of the child.

Please write clearly in blue or black ink, place only one character in each box, and use all uppercase letters; this form will be read by a computer.

(1) On what date is this form being filled out?

(2) What is the participant's birth date?
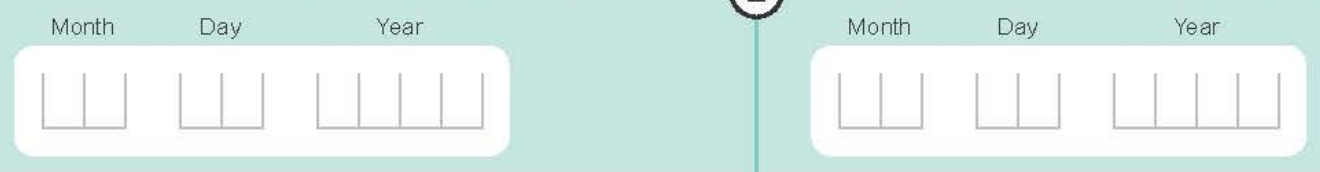

(3) Participant's identification information:

First name

Last name

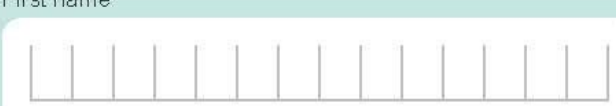

Last name

Social Security number

Medicaid ID number

Gender
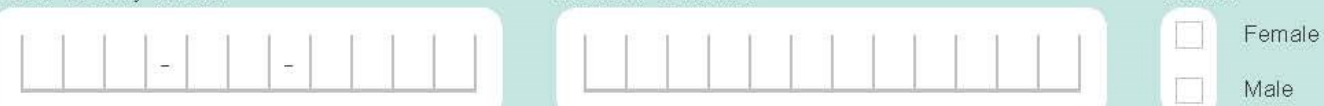

Street address

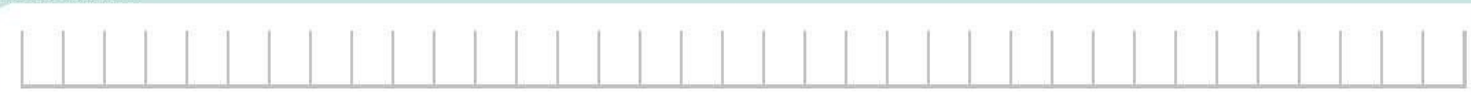

City

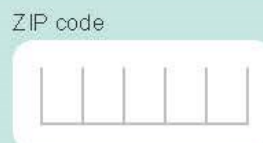

Phone number

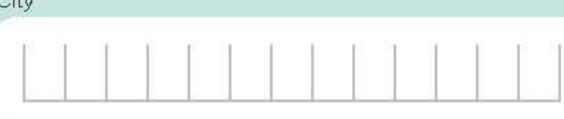

$-1$

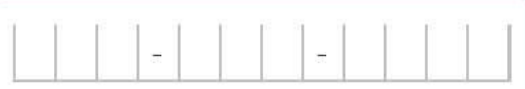

(4) Infant's identification information:

First name

Last name
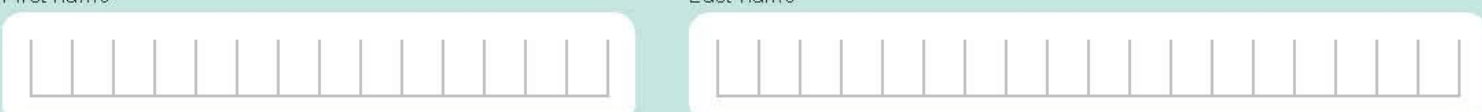

Social Security number (if known)

Medicaid ID number (if known)

Sex
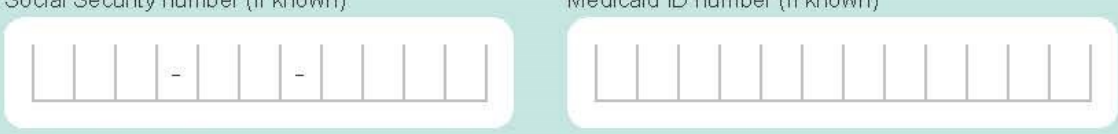

Female

Is the infant's address the

same as the participant's?

प Yes

D No

If you marked yes, you may skip the address

fields to the right. If no,

complete these fields.

Street address

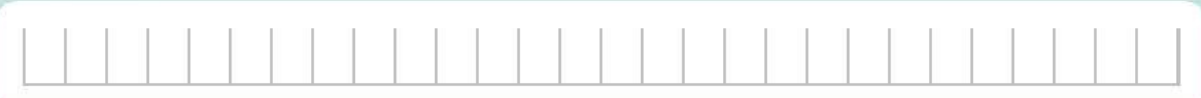

City

ZIP code
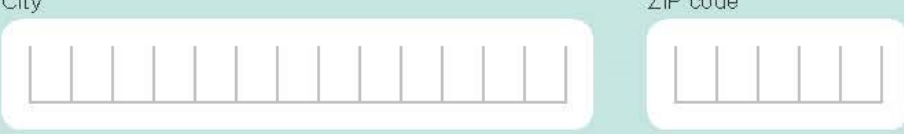


\section{Birth form}

Participant's last name and birth date
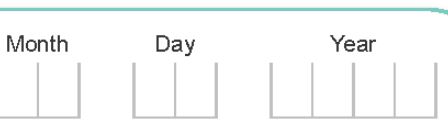

(5) On what date was the infant born?

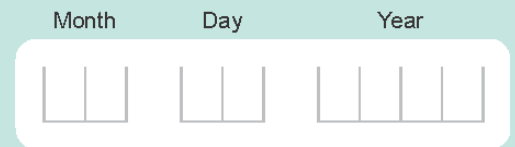

(9)

Where does the infant sleep?
(Please check all that apply.)

6

Was this a multiple birth?

$\square$ No

Yes, twins

Yes, triplets

If more than one child was born, please use multiple copies of this form for the additional child(ren).

(7) What is the infant's race/ethnicity?

(Please check all that apply.)

White

Black or African American

Hispanic or Latino

Asian

Native Hawaiian or Pacific Islander

American Indian or Alaska Native

Other (please specify)

(10) What position is the infant put to sleep in most frequently?

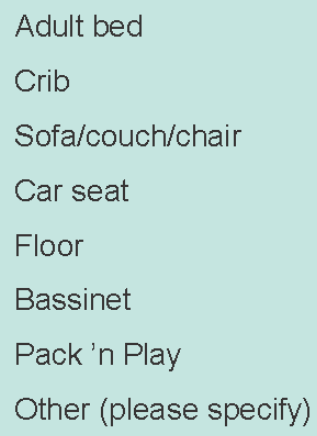

$\square$ On their back

On their side

On their stomach

Does the infant ever share a sleeping surface with any other people or a pet? $\square$ Yes $\square$ No

The final two questions on this form do not apply to participants in a fatherhood program.

(8) How is the infant being fed?
$\square$ Breastfeeding only
Some breastfeeding, some formula
Formula only

(12) Did the participant receive treatment with progesterone during this pregnancy?

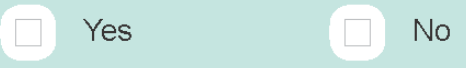

(13) How many total prenatal visits did the participant attend during this pregnancy?

Form administrator's first name

Form administrator's last name

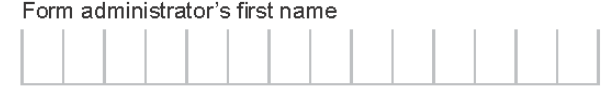

Organization/program name

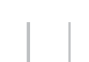

When complete, this form can be faxed to 614-293-4183 or scanned and emailed to oeieval@osumc.edu. For questions about this form, call 614-366-8897 or email oeieval@osumc.edu. 


\section{Ohio \\ Department of Medicaid \\ THE OHIO STATE UNIVERSITY \\ COLLEGE OF MEDICINE \\ OhioHigherEd}

\section{Exit form}

Complete this form as the participant exits the program or when this is likely to be the final encounter.

Please write clearly in blue or black ink, place only one character in each box, and use all uppercase letters; this form will be read by a computer.

(1) On what date did the participant exit the program?

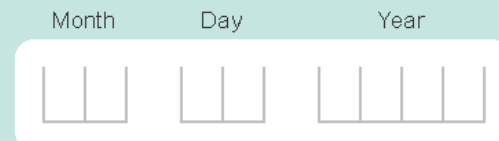

(2) What is the participant's birth date?

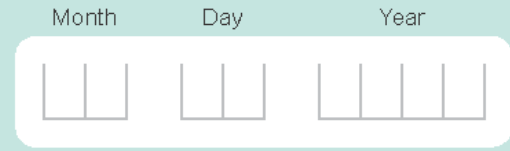

(3) Participant's identification information:

First name

Last name
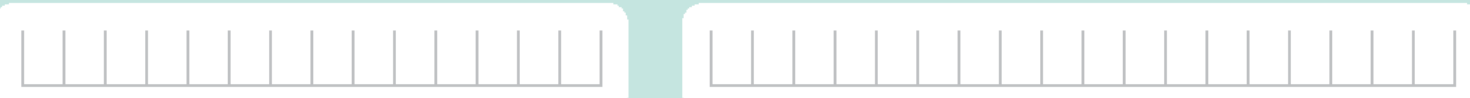

Social Security number

Medicaid ID number

Gender
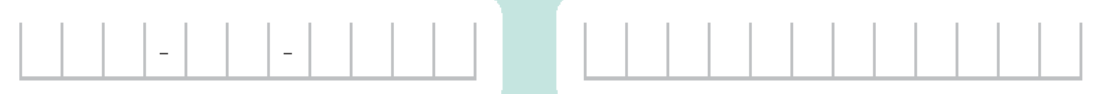

$\square$ Female

Street address

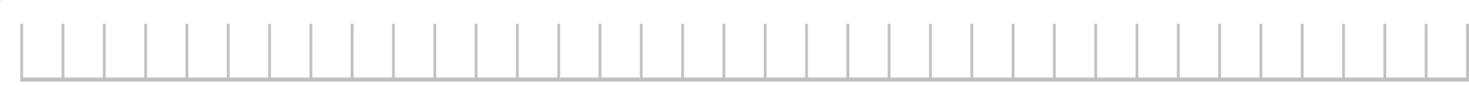

City

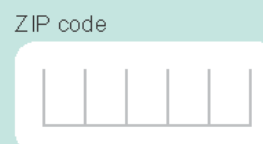

Phone number

(4) Infant's identification information:

First name

Last name

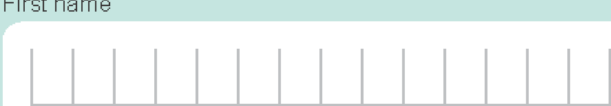

Social Security number (if known)

Medicaid ID number (if known)

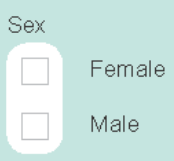

Is the infant's address the

same as the participant's?

Yes

No

If you marked yes, you may skip the address

fields to the right. If no

complete these fields.

Street address

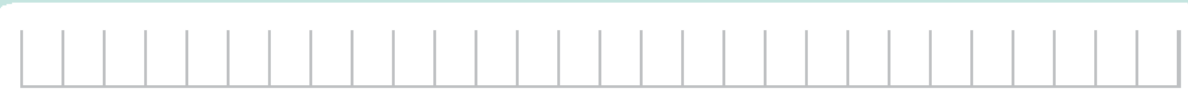

City

ZIP code

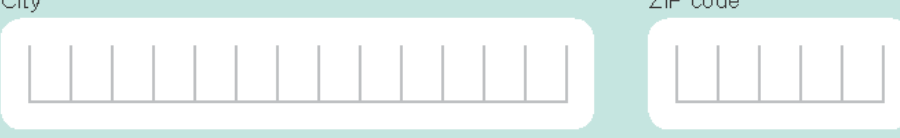




\section{Exit form} Participant's last name and birth date Month Day

(5) On what date was the infant born?

$\begin{array}{ll}\text { Month } & \text { Yay } \\ |+| & |+|\end{array}$

6) Was this a multiple birth?
$\square$ No
Yes, twins
Yes, triplets

If more than one child was born, please use multiple copies of this form for the additional child(ren).

(7) What kind of housing does the participant have?
D Live in house/apartment owned by participant
Live in house/apartment owned by family/ friends
Live in rented house/apartment
Live in shelter or group home
Public housing
Homeless
Other (please specify)

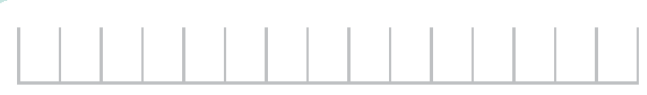

(8) Please check any home safety issues the participant is experiencing.

No working smoke detectors

Firearms or weapons in home

Smell of gas/mildew/mold

Pests suspected/present

Smoking in house

Windows/doors do not lock appropriately

Garbage/clutter/unclean environment

Drugs/chemicals/cleaning supplies within reach
(9) What is the participant's employment status? (Please check all that apply.)

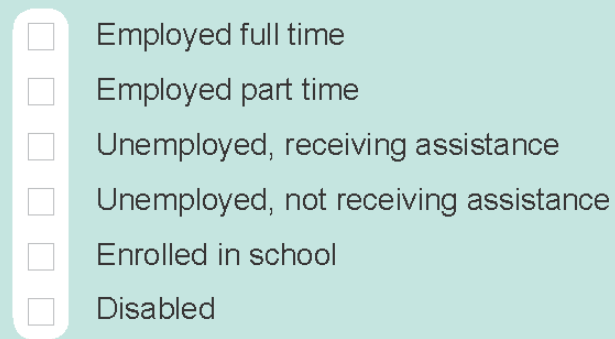

(10) Is the participant currently enrolled in any of the following public assistance programs? (Please check all that apply.)

Women, Infants and Children (WIC)

Supplemental Nutrition Assistance Program (SNAP/food stamps)

Temporary Assistance for Needy Families (TANF)

Disability or unemployment

Other prenatal/infant health program

Housing assistance program

Child care program

Food assistance program

Exercise/health promotion program

Educational/employment assistance program

Mental health/substance abuse program

Don't know

Other (please specify)

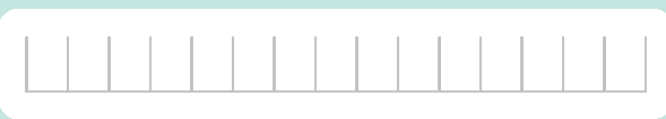

(11) Does the participant have adequate access to food?

$\square$ Yes $\square$ No 


\section{Exit form}

Participant's last name and birth date
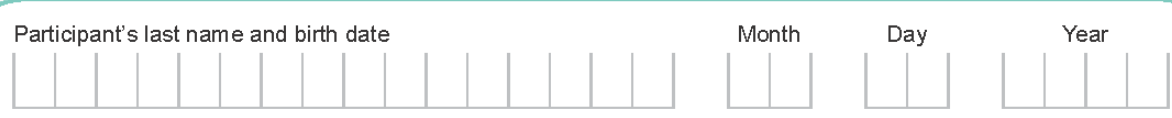

Page 3 of 3

(12) How many well-child medical visits did the participant and child attend to check on the child's heath?

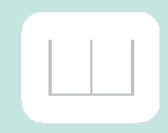

(15) Has the child received recommended immunizations?

$\square$ Yes $\square$ No

13. How many ER/urgent care visits were attended for the child or participant since the child's birth?

(16) When the participant is away from home, where does the child or children go for child care?

14. If the answer to \#13 was more than zero, what were the reasons for the visit/visits?

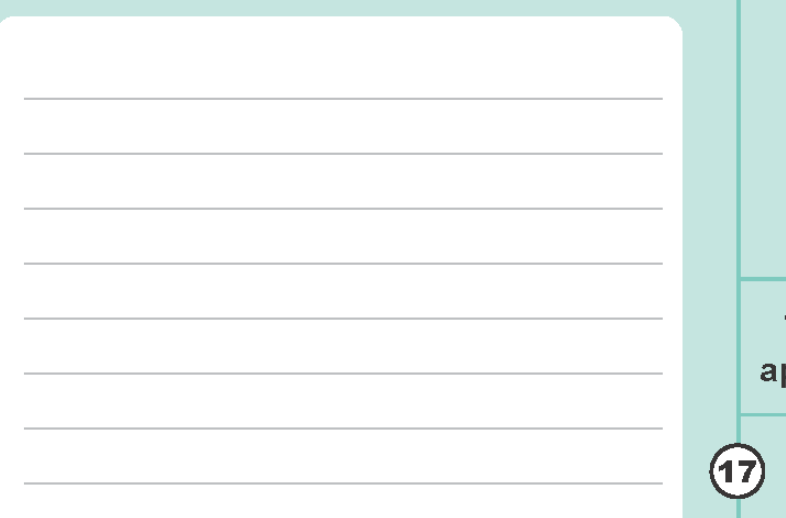

